\title{
Climate Change Perception and Adaptation in a Remote Costa Rican Ag- ricultural Community
}

\author{
Carolyn E. Smith ${ }^{1}$ and Maren Oelbermann*,2 \\ ${ }^{I}$ Department of Geography and Environmental Studies, Faculty of Arts and Social Sciences, Carleton University, \\ Ottawa, ON, K1S 5B6, Canada \\ ${ }^{2}$ Department of Environment and Resource Studies, Faculty of Environment, University of Waterloo, Waterloo, ON, N2L \\ 3G1, Canada
}

\begin{abstract}
Current agroecosystem management practices in tropical latitudes may not be an economically feasible and an effective long-term adaptation strategy to climate change. As such, implementing, improving and refining sustainable land management practices may be a more effective adaptation strategy. This study determined the perception and knowledge of climate change by landowners in a remote Costa Rican agricultural community, and evaluated the type of sustainable agricultural practices currently implemented and how such practices could also serve as a climate change adaptation strategy. Based on this information, recommendations for successful adaptation applicable to other communities were also discussed. This study showed that community members observed changes in local weather patterns over the past decade, which paralleled changes in the distribution patterns of vegetation and wildlife. Results also showed that community members had a good understanding of climate change and its potential impact(s) on agricultural production. Community members were continually striving to implement long-term sustainable agroecosystem management practices to maintain productivity, integrity and agroecosystem resilience while also meeting economic and socioecological needs. For example, implementing seedbanks helped to improve the quality of crops and provided a source of seeds adapted to current climate conditions. Other adaptation strategies included agroforestry for soil and water conservation and as a source of fruits, nuts and forage for people and livestock. The use of livestock nutritional supplements to offset low-quality forage during the now more intense dry season, compared to previous dry seasons, were also used as an adaptation strategy. An affiliation with social networks to help access resources and implement sustainable agriculture and climate change adaptation strategies were essential in this community. Based on surveys with community members, this study developed a 3stage plan for developing successful adaptation programs for application in other small agricultural communities in tropical latitudes.
\end{abstract}

Keywords: Agroforestry, global warming, agricultural production, seedbank, resilience.

\section{INTRODUCTION}

The conversion of natural grasslands and forests to agricultural production systems in developing countries are the single most important anthropogenic sources of greenhouse gases (GHGs) contributing to global warming [1]. Although our scientific understanding of climate change has substantially progressed over the past 10 years [2], the effects of climate change on ecosystem resilience remain unknown. Catford [3] noted that climate change will affect the distribution and productivity of life-sustaining agricultural crops and livestock in tropical biomes. Deforestation and intense agricultural production not only contributes to the accumulation of GHGs in the atmosphere, thereby affecting local, regional and global weather patterns, but it also leads to the depletion of the global soil organic matter (SOM) and soil organic carbon (SOC) pools, further impacting soil fertility and crop

*Address correspondence to this author at the Department of Environment and Resource Studies, Faculty of Environment, University of Waterloo, Waterloo, ON, N2L 3G1, Canada; Tel: + (519) 888-4567 Extension 37552; Fax: + (519) 746-0292; E-mail: moelbermann@uwaterloo.ca productivity. As a result, the United Nations Development Program suggested that millions of people may be facing shortages of food and fodder as the intensity and rate of precipitation during the rainy season are increasing while dry seasons are longer, drier and hotter. For example, In Central America, a prolonged dry season in 2009 resulted in the loss of subsistence crops leading to food shortages.

One of the challenges under current climate change scenarios is to maintain agricultural productivity to meet current and projected trends in food production, while at the same time minimizing GHG emissions and increasing carbon (C) sequestration from such practices. This, coupled with largescale land, soil, and water degradation, will challenge the long-term and sustainable production of agricultural resources that promote food security and sustainable livelihoods. Achieving food security under a changing climate requires an initiation and diversification of and a substantial increases in, sustainable agricultural production to maintain or improve access to nutritious food (Fig. 1).

Traditional coping mechanisms, including conventional agroecosystem management practices may not be an eco- 


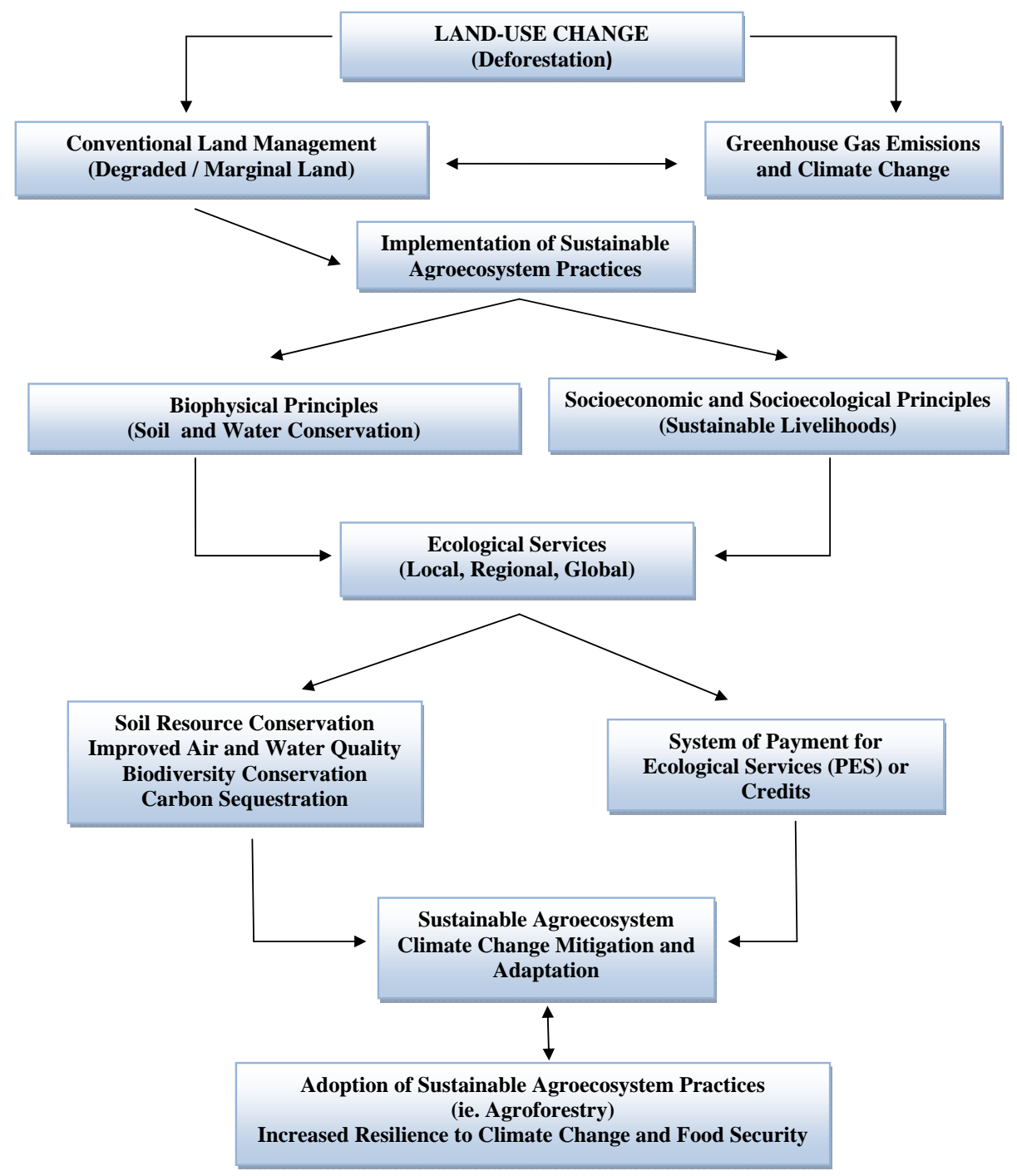

Fig. (1). Conceptual model presenting the logical progression from deforestation and the creation of marginal land with poor productivity to the implementation of agroforestry systems for climate change mitigation and adaptation, while also providing ecological services.

nomically feasible and long-term sustainable adaptation strategy, especially for those communities already experiencing food security related issues. Current research efforts point to a greater incidence of pest, disease and weed infestations in conventional agoecosystems as a result of climate change [4]. Additionally, changes in climate may alter the nutritional quality of crops and fodder, which may require changes in the composition and application rate of inorganic fertilizers and use of mineral supplements in livestock [5]. The effects of climate change on soil processes may also directly impact plant growth and productivity [5]. Therefore, the implementation, improvement and refinement of sustainable land management practices are essential climate change adaptation strategies. Sustainable agroecosystem land management practices including the establishment of seedbanks for the long-term storage of agricultural seeds, improved livestock forage quality, and agrofoerstry practices are crucial for maintaining ecological, economic and social security. Agroforestry is defined as the deliberate integration of woody species with agricultural crops and/or pastures on the same land-unit resulting in the integration of economical and ecological interactions between trees and the other components of the system [6].
Integrating trees on land and/or homesteads controls runoff and soil erosion, thereby conserving levels of SOM and soil nutrients, increases water availability to crops and provides a long-term sustainable source of fruit, nuts, and fodder to people and livestock. Due to their structural complexity, sustainable agroecosystem land management practices, including agroforestry, may be more resilient to climate change and thereby simultaneously address social, economic and ecological security. Additionally, sustainable land management practices can provide ecological services, and therefore can be included in a payment for environmental services (PES) or credit system. Ecological services such as soil, water and biodiversity conservation, and $\mathrm{C}$ sequestration, are derived at the farm- and / or landscape-scale but are enjoyed by society at regional- and / or global-scales [7].

The goal of this study was to evaluate, using formal interviews, the integration of climate change information into sustainable land management practices in a small agricultural community in Durika, Costa Rica. The specific objectives of the study were evaluate how Durika community members perceived climate change, what type of sustainable agricultural management approaches they implemented and how these practices could also be used as climate change adapta- 
tion strategies. We also evaluated how this information could be used to successfully aid other agricultural producers to adapt to climate change through the development of a 3stage climate change adaptation plan. Information gained from this study will provide further insight into how climate change adaptation strategies can be integrated into sustainable land management practices.

\section{STUDY SITE}

This study was conducted in Durika, a remote community in Costa Rica's Talamanca mountain range. Durika is a sustainable agricultural community that was established by ecologists, academics, health and other professionals from Costa Rica in order to restore the degraded land as a result of conventional agroecosystem management practices. Durika is located $13 \mathrm{~km}$ northeast of Buenos Aires $\left(09^{\circ} 15^{\prime} \mathrm{N}\right.$, $\left.83^{\circ} 15^{\prime} \mathrm{W}\right)$. This region of Costa Rica is characterized as humid tropical with mean temperatures ranging from $22^{\circ} \mathrm{C}$ in the rainy season to $27^{\circ} \mathrm{C}$ in the dry season. The average annual precipitation of this region is $3500 \mathrm{~mm}$, with a distinct dry season from November to April and a distinct wet season from May to October. The mean number of sunshine hours in this region is $6 \mathrm{~h}$ /day from November to April, and 4 $\mathrm{h}$ /day from May to October. The elevation of this region varies from 1400 to $2800 \mathrm{~m}$ above sea level. The community of Durkia is located $1650 \mathrm{~m}$ above sea level and this area is affected by north to northeast trade winds reaching speeds up to $97 \mathrm{~km} / \mathrm{h}$ during the dry season.

Land-use management practices surrounding Durika include large-scale pineapple (Ananas comosus) (L.) Merr. production at lower elevations, and cattle production at higher elevations. A large proportion of the forest has been cleared resulting in large-scale erosion, which is further exacerbated through unsustainable livestock land management practices. Over the past decade there has been a significant loss in the number of small farms in this region, which have been replaced by commercial pineapple, banana (Musa balbisiana Colla), and sugar cane (Saccharum officinarum L.) producers. Small- and medium-scale agricultural producers in this region practice slash-and-burn agriculture for selfsustenance and small market production. These agricultural producers manage a combination of land management practices including livestock, coffee (Coffea arabica L.), maize (Zea mays L.) and / or beans (Phaseolus spp.).

The community also includes an indigenous population and agricultural producers that became part of Durika since its establishment in 1995. Durika has 30 permanent members consisting of agricultural producers, scientists and ecologists, in addition to others that visit Durika over the short-term to conduct research. The current location of Durika was formerly a livestock production system that led to large-scale land degradation and erosion forcing the previous landowners to abandon the area. Subsequently the land was purchased by a group of Costa Rican citizens concerned about the large-scale land degradation in this area. Unlike most agricultural producers in the region, Durika members began producing agricultural crops with knowledge of the principles of ecology, climate change, economics, and sustainable land management practices. They used these principles to restore the land including the integration of agroforestry practices to conserve soil and water. Their agricultural prac- tices include mixed farming with goats, vegetables, fruit and coffee. The overall principles of the community are to establish self-sufficiency; to improve the quality of life for Durika community members; to create social, community, and educational programs; to protect the environment and ecosystems surrounding Durika; to promote scientific research; and to maintain traditional land management practices.

\section{SAMPLING METHODS}

A total of 10 community members were chosen using stratified random sampling, in addition to the community leader and founder of Durika, due to his knowledge on how the community has adapted to the current conditions since its establishment. Each person selected for this survey was asked questions based on three different themes: 1) observations and perceptions about climate change; 2) they type of climate change adaptation strategies being implemented and the outcome of these implementations; 3 ) the adaptive capacity to climate change of agricultural producers outside the Durika community. Textual data included information provided by community members that elaborated on questions on the survey as well as visual observations related to the landscape and the different land management practices implemented. Data gathered from the surveys were transcribed and organized manually and by QSR NVivo® software (QSR International, Melbourne, Australia).

\section{RESULTS AND DISCUSSION}

\section{Observations of a Changing Climate in Durika}

Durika records daily weather information for the Costa Rican Weather Bureau. From this data, and information from the surveys with the agricultural producers of Durika, they noted dramatic changes in Durika's climate over the past 10 years. Prolonged and hotter dry season over the past decade were observed by Durika community members. These observations also coincided with those predicted by climate change models of the IPCC [8]. They also observed major changes in the quantity and intensity of precipitation during the rainy season over the past decade. For example, in 2005, they recorded an annual amount of precipitation of $5000 \mathrm{~mm}$ which was well above the mean annual precipitation of 3500 $\mathrm{mm}$. These intense rainfalls led to landslides in agricultural fields and in areas covered with primary forest. According to Durika community members, an area covered by primary forest was not previously observed to be susceptible to landslides. The heavy rains in 2005 were also noted by the Costa Rican Weather Bureau who issued a heavy rain weather bulletin for the region surrounding Buenos Aires, and issued a state of emergency in September 2005 [9]. Although daily weather information has been recorded in Durkia since 1995; long-term data is currently lacking in order to determine trends in climate change in this and other areas of Costa Rica [10]. The observed and measured changes in quantity and intensity of precipitation in Durika coincided with those predicted by the IPCC and are associated with extreme weather events that are increasing in tropical regions [10].

Ecologists in Durika attributed altered patterns in the distribution of vegetation and wildlife to changes in climate. For example, they observed that the Ferdelance (Bothrops atrox L.), which usually resides along the coasts of Costa 
Rica, was more commonly spotted in the mountains of Durika over the past four years. The numbers of amphibian species has also decreased significantly, especially along rivers. Durika community members suggested that a decline in amphibian numbers is due to climate change rather than loss of habitat and land-use change. This is because La Amistad International Park, Costa Rica's largest and most remote protected area and is also surrounded by other parks and reserves, is located upstream of Durkia. Such a large protective area surrounding Durika would provide continuous habitat for amphibians in this area. Walther et al. [11] noted that international efforts are currently underway on evaluating the impact of climate change on amphibians. Results from such research have shown that the observed decline in amphibian number, diversity and distribution in tropical biomes is correlated to climate change and climate change-related disease outbreaks rather than habitat loss [11, 12].

Based on information obtained from Durika, the more intense dry and rainy seasons have not posed as a major peril to agricultural productivity to date. However, Durika's agricultural producers are vigilant of their livestock and families due to the greater visibility of the Ferdelance. Changes in crop and livestock productivity and disease outbreaks have also not been observed to date as a result of the changing climate patterns. However, a Durika ecologist noted that such changes will likely become more common over the next decade as more severity in local weather patterns is expected as a result of global warming. Community members anticipate that they will be forced to adjust their agricultural land and livestock management practices because there may be a shift in wildlife habitat and in the pattern of vegetation distribution and productivity. These adjustments, coupled with changes in predator-prey relationships, greater occurrence of disease and pest outbreaks and decreased crop and forage productivity, will challenge agricultural producers in tropical latitudes [13].

\section{Sustainable Agriculture Adaptation Strategies in Durika}

Durika community members indicated a good understanding of climate change and its potential impact(s) on agricultural production. As a result, Durika's agricultural producers are continuously striving to implement long-term sustainable land management practices. Such practices help maintain agroecosystem integrity, resilience, and productivity while at the same time supporting economic and socioecological needs. The primary initiatives implemented by Durika community members, within the framework of sustainable agroecosystem production systems, also indirectly served as climate change adaptation strategies. Such initiatives included the use of seed banks, agroforestry for soil and water conservation and fruit and nut production, and the use of nutritional supplements for livestock.

A seedbank is the long-term storage of crop or vegetable seeds, used as a reserve when seed availability is scarce or has been destroyed. Seedbanks also guard against natural disasters and disease outbreaks. Since Durika's community members have a good understanding of climate change and its potential impacts on crop productivity, agricultural producers implemented a seedbank. The seedbank in Durika helps to improve the quality of agricultural crops produced in the community, and their seeds are adapted to current cli- matic conditions. This provides the community with a seed reserve, ensuring food security, during a catastrophic event. Malakata [14] noted that seedbanks are also an important climate change adaptation strategy as they provide the genetic material to improve seed varieties and diversity. However, Arocena and Senker [15] observed that the number of agricultural producers saving seeds, throughout Latin America, has declined over the past 20 years. This is due to the commercialization of agriculture and the production of transgenic crops that agricultural producers are encouraged to use due to their greater productivity. Due to the low germination rate of seeds from transgenic crops, seeds are not saved and are not incorporated into a seedbank.

Agroforestry systems were also implemented in Durika as part of their sustainable agriculture production systems. Trees, including Quercus spp., Samanea saman (Jacq.)Merr., Cedrela spp., Calophyllum antillanum Britt., Virola sebifera Aublet., Persea americana P. Mill., Symphonia globulifera L., were integrated on agricultural land and on surrounding homesteads. These trees provided ecological services such as the protection of soil from erosion during heavy rainfall and prevented stream sedimentation. Herbaceous plants such as banana and Mangifera indica L. (mango) were used for fruit production and typically located on homesteads. Durika community members understood that trees play an important role in conserving soil and water, especially on steep mountain slopes. They acknowledged that the trees in their agroforestry systems also played an important role in protecting their livelihoods by providing essential ecological services. For example, they noted that many of Durika's buildings and homesteads, because of their location on steep mountainsides, would be susceptible to damage from erosion caused by intense rainfall events (Fig. 2). Due to the recent increase in rainfall intensity, Durika's agricultural producers and other community members have made a concerted effort in intensifying their reforestation efforts using agroforestry systems. These trees would provide a dual purpose by providing food and / or shade for livestock or people, and provide an ecological service by protecting their buildings.

The conservation and protection of freshwater ecosystems plays a key role in sustainable agroecosystem land management practices. For example, Pretty et al. [16] examined water use and crop productivity in several countries, including Costa Rica. They found that the conservative use of water and rigorous irrigation schedules was directly linked to the food security, since this led to an increase in the number of crops and crop productivity per unit area. With the current trend of rising temperatures and lower quantity of rainfall during the dry season as a result of global warming, water conservation efforts are essential in Durika. Community members implemented water conservation measures including the use of agroforestry systems by integrating drought tolerant tree species and grasses such as Brachiaria spp. on their land. Additionally, rainwater and overflow water collection and storage vessels were installed. Rainwater collected during the rainy season is stored ensuring a sufficient supply of water for livestock and crops during the dry season. The community has only one mountain stream which serves as a source of water for livestock and people. As such, Durika implemented agroforestry systems, such as riparian plantings, to protect this source of water and ensure water quality. 


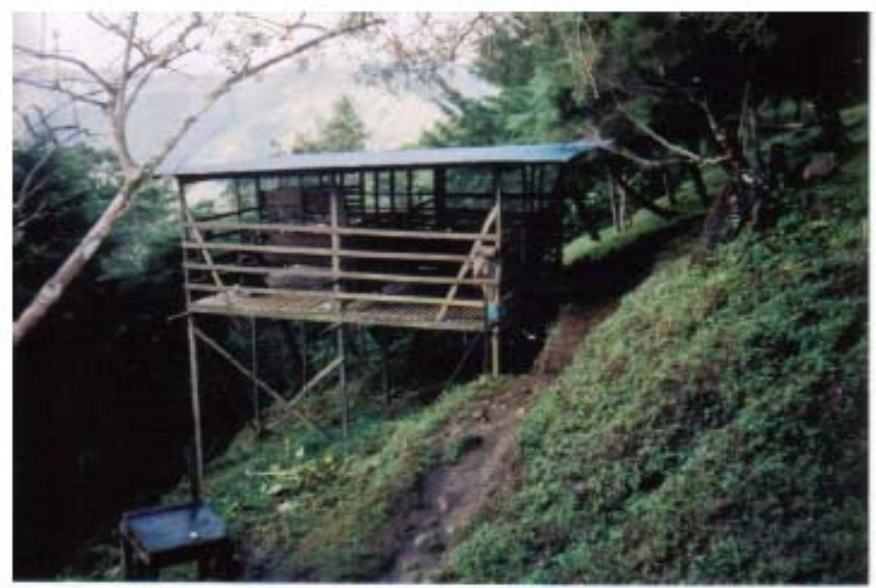

Fig. (2). The effectiveness of integrating trees on to homesteads and agricultural land to protect buildings constructed on steep slopes from erosion during heavy rainfall events in Durika, Costa Rica.

When forage productivity and quality is low during the dry season, Durika's agricultural producers feed their livestock nutritional supplements such as molasses, slow-release urea, and mineral and nutrient concentrate. Although the agricultural producers are working toward sustainable agroecosystem production, they are still required to feed their livestock nutritional supplements to ensure sufficient milk and meat production. Community members, however, noted that the minimal requirement for livestock nutritional supplements is increasing annually in order to meet milk and meat production of self sustenance. They attributed this situation to a decline in forage quality and productivity as a result of a hotter and more intense dry season over the past decade.

\section{Implications and Recommendations for Climate Change Adaptation in Durika}

The implementation of sustainable agroecosystem management practices in Durika likely contributed to a greater resilience of crops and livestock during the extended dry season and has led to an overall greater adaptive capacity to climate change by Durika community members [17]. Due to the diversity of expertise in Durika, ranging from agricultural producers to ecologists and academics, community members were able to combine and integrate different types of learning and associations with social networks, which helped them to enhance their adaptive capacity. Additionally, Durika has also developed partnerships with the National Institute for Learning (INA), the National Biological Institute (INBIO), the University of Costa Rica, and the Organization of Tropical Studies (OET). Information gained from these social networks combined with their own knowledge on implementing sustainable agricultural land management practices has further contributed to their adaptive capacity to climate change. Such an association with social networks will also make the community more robust to other current and future challenges that may arise as a result of global change.

Based on the surveys with Durika community members, several themes emerged that played a major role in their implementation of sustainable agricultural land management practices within the framework of climate change adaptation strategies (Fig. 3). Community members emphasized that climate change adaptation strategies should also meet their goal of sustainable agriculture. They noted that this would ensure their farming practices remain resilient to climate change as well as social, political and economic factors such as recessions or changing markets. Similarly, the Countryside Agency of England is promoting initiatives that encourage sustainable agricultural land management practices parallel to climate change [18].

Members of Durika also expressed that climate change adaptation strategies should pose little risk and would ensure agricultural productivity, food security and sustainable livelihoods. If the adaptation strategy leads to a short-term decline in agricultural productivity, Durika's members would likely not implement such a plan. However, if the climate change adaptation strategy maintained or increased agricultural productivity, they would most likely implement such an approach. For example, in Canada agricultural producers based the implementation of climate change adaptation strategies on issues related to markets, profit, and capital required to implement a particular land management practice [19]. Wall and Smit [19] noted that the adaptation strategy must not hinder the agricultural producer's ability to support their current needs.

Over the past 20 years, Durika's community members have increased the number of organizations from which they obtain information. These organizations offer information and new technologies that provided incentives to adapt and to implement different adaptation strategies [20]. Gallopin [17] noted that establishing, maintaining, and improving social networks with academic institutions, governmental and non-governmental organizations plays a key role in the adaptation and implementation of climate change adaptation strategies. In addition to integrating adaptation strategies suggested by governmental and non-governmental organizations, community member in Durika have also taken local indigenous knowledge into consideration and incorporated them into their land management practices. Nyong et al. [21] suggested that the inclusion of indigenous knowledge, when available, into a well-structured climate change adaptation program also contributes to agricultural sustainability and resilience to climate change. 


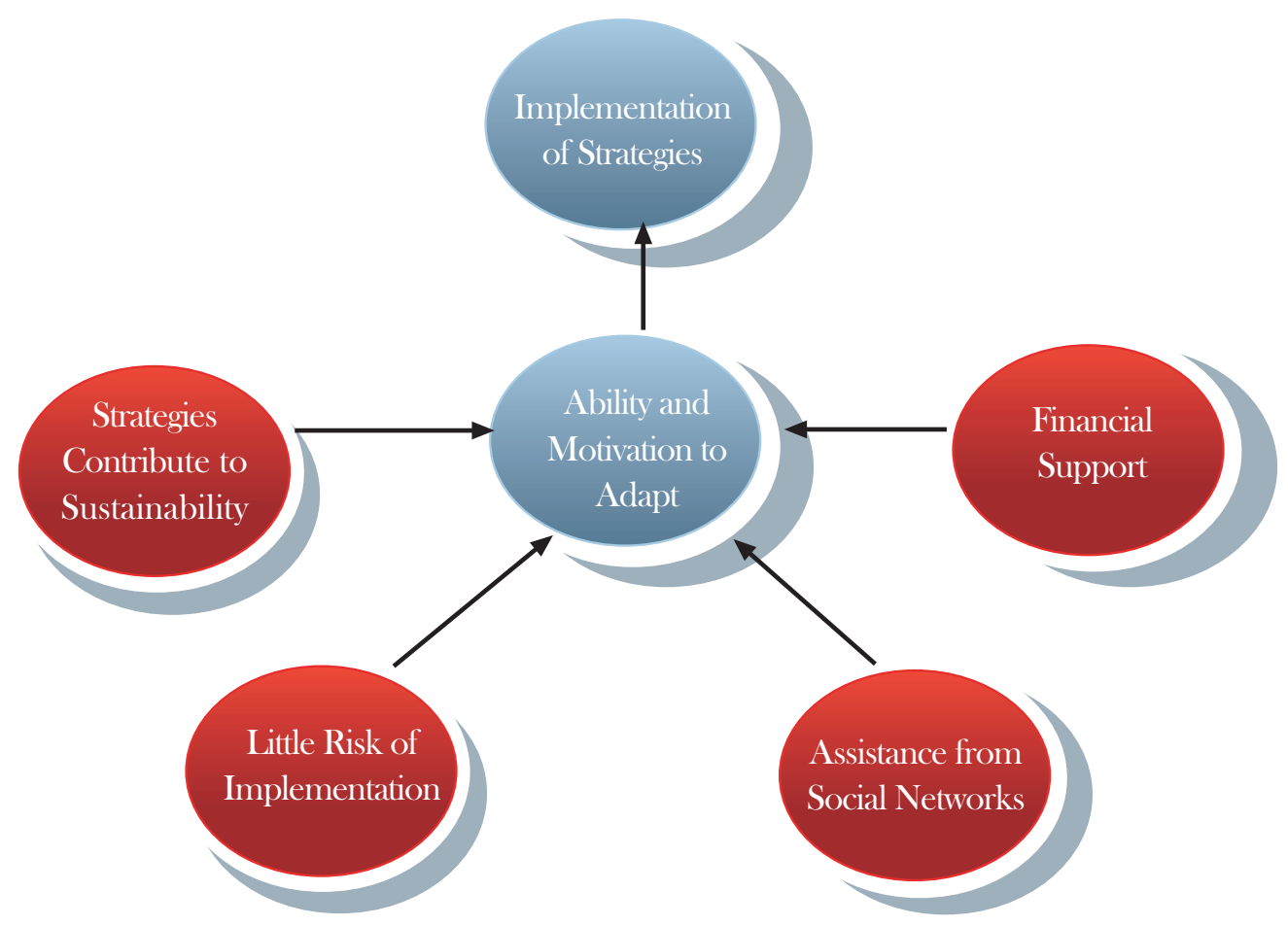

Fig. (3). Factors influencing the ability and motivation of agricultural producers to implement climate change adaptation strategies collected from interviews in the community of Durika, Costa Rica.

Based on results of this study, a 3-stage plan to help implement successful adaptation programs for application in other small agricultural communities in tropical latitudes was developed (Table 1). Governmental and non-governmental organizations as well as other social networks play a key role in consulting with agricultural producers in order to acquire baseline biophysical data (i.e. soil quality, land management practices, land degradation, major issues facing crop and / or livestock production, weather data) and socioecolgoical information (stage 1). Once baseline information has been collected, the implementation of climate change adaptation strategies (stage 2) occurs. During this stage, agricultural producers are encouraged to develop their own strategies and share their ideas with other community members and with social networks. Agricultural producers are also encouraged to implement strategies, through financial aid, that offer multiple benefits such that provided by agroforestry systems which can be integrated in to a PES. The follow-up phase (stage 3) consists of regular consultation, evaluation and education with governmental, non-governmental and / or social networks to ensure the success of the implemented climate change adaptation strategies. This also provides an opportunity to make any adjustments and improvements to the recently implemented climate change adaptation strategy.

In addition to a close association with governmental and non-governmental organizations, Durika also received financial incentives from grants and donations to help implement sustainable agroecosystem land management practices and climate adaptation strategies. Without such incentives, Durika would not have implemented such strategies. Nhemachena and Hassan [20] suggested that financial incentives help with payment for transaction costs associated with implementing climate change adaptation strategies. Agricul- tural communities surrounding Durika have not received any financial incentives to date to help them adapt to climate change. The International Fund for Agricultural Development (IFAD) noted that most small-holder agricultural producers do not receive financial incentives to help them implement climate change adaptation strategies [22]. The IFAD also noted that without financial support, climate change adaptation strategies are not typically implemented by agricultural producers and thereby enhancing their vulnerability to food insecurity.

\section{CONCLUSIONS}

Durika's community members have observed a general increase in temperature and decrease in precipitation during the dry season, and a greater quantity and intensity of precipitation during the rainy season. These observations also coincide with those predicted by the IPCC's climate change models. As a result of Durika's mandate to practice sustainable agriculture in a previously degraded landscape, their land management practices also parallel those of climate change adaptation strategies. As such, Durika community members have established seedbanks, implemented agroforestry systems, and made a concerted effort in conserving soil and water. However, the adaptive capacity to climate change is very closely associated with economic factors, particularly the amount of financial resources available to the agricultural producer. Community members were not willing to implement climate change adaptation strategies if these were not within the framework of sustainable agriculture and / or lead to a short-term decrease in agricultural productivity because of potential impacts on food security and sustainable livelihoods. Results from this study showed that an affiliation with social networks to help access resources and implement 
Table 1. Three-Stage Plan for Developing Successful Adaptation Programs Applicable to Other Communities in Tropical Climates. This 3-Stage Plan is Based on Surveys with Durika Community Members, Costa Rica

\begin{tabular}{|c|c|c|}
\hline & ACTION & DESCRIPTION \\
\hline \multirow[t]{2}{*}{ Stage 1} & $\begin{array}{l}\text { Acquisition of baseline } \\
\text { data }\end{array}$ & $\begin{array}{l}\text { - Acquisition of baseline biophysical data on current land management practices, soil quality, land degradation, } \\
\text { weather data } \\
\text { - Acquisition of social and economic information of agricultural producers } \\
\text { - Use of GPS for exact location of each agricultural producer's land and farmyard }\end{array}$ \\
\hline & $\begin{array}{l}\text { Consultation with Ag- } \\
\text { ricultural Producers }\end{array}$ & $\begin{array}{l}\text { - Arrange meeting times with agricultural producers outside of the sowing and crop harvest seasons } \\
\text { - Determine what land management practices are currently used and determine if further help in implementing } \\
\text { new technologies is required } \\
\text { - Determine current state of knowledge of agricultural producers on sustainable agroecosystem management prac- } \\
\text { tices, climate change, climate change adaptation } \\
\text { - Determine the main issues facing agricultural producers and use this information to develop strategies that help } \\
\text { mitigate these issues } \\
\text { - Provide agricultural producers with information on climate change and sustainable agriculture and educate them } \\
\text { on the importance of long-term goals versus short-term gains } \\
\text { - Link agricultural producers to local social networks, governmental and non-governmental organizations } \\
\text { - All discussions should be open-ended allowing the agricultural producer to voice their opinions and concerns }\end{array}$ \\
\hline Stage 3 & Follow-up & $\begin{array}{l}\text { - Continue regular consultation meetings to confirm the success of the implemented strategies and provide further } \\
\text { information to agricultural producers via social networks, governmental and non-governmental organizations } \\
\text { - Evaluate the success of the program through the collection of data based on the previously collected baseline } \\
\text { information on biophysical, social, and economic characteristics, and on the implemented land management prac- } \\
\text { tices and climate change adaptation strategies } \\
\text { - Make any adjustments to the implemented strategies if needed } \\
\text { - Continue to educate agricultural producers on the importance of developing a long-term plan for their land and } \\
\text { families for climate change and sustainable agriculture }\end{array}$ \\
\hline
\end{tabular}

sustainable agriculture and climate change adaptation strategies were essential.

It is imperative that future research examines the implications of climate change on various ecological systems, including its impact on vegetation and wildlife distribution, crop and livestock productivity, and soil fertility. This will help develop a better understanding on the type of adaptation strategies necessary as well as decrease the cost of such implementation strategies. The long-term collection and availability of weather data in remote communities in Costa Rica is imperative. As financial incentives become available and agricultural producers begin to adapt climate change adaptation strategies, the availability of weather data will help assist in the development and implementation of the most effective strategy. Future research efforts should also incorporate information from large-scale coffee and fruit producers in Costa Rica because of their large contribution to that countries' GDP.

\section{ACKNOWLEDGEMENTS}

Financial support was provided by IICA-Canada. We also thank Durika community members, especially German Cruz Villanueva, Eugenio Garcia, and Vilma Rodriguez.

\section{REFERENCES}

[1] Lal R. Agricultural activities and the global carbon cycle. Nutr Cycl Agroecosyst 2004; 70: 103-16.
[2] Füssel HM. An updated assessment of the risks from climate change based on research published since the IPCC Fourth Assessment Report. Climat Change 2009; 97: 469-82.

[3] Catford J. Food security, climate change and health promotion: opening up the streams not just helping out down-stream. Health Promot Intern 2008; 23: 105-8.

[4] Newton PCD, Carran RA, Edwards GR, Niklaus PA, Eds. Agroecosystems in a changing climate. USA: CRC Press 2007.

[5] Niklaus PA. Climate change effects on biogeochemical cycles, nutrients, and water supply. In: Newton PCD, Carran RA, Edwards GR, Niklaus PA, Eds. Agroecosystems in a changing climate. USA: CRC Press 2007; pp. 11-52.

[6] Young A. Agroforestry for Soil Management. CAB International, Wallingford, UK 2002; p. 320

[7] Jose S. Agroforestry for ecosystem services and environmental benefits: An overview. Agroforestry Syst 2009; 76: 1-10.

[8] Parry ML, Canziani OF, Palutikof JP, van der Linden PJ, Hanson CE, Eds. Climate Change. Impacts, adaptation, and vulnerability. Contribution of Working Group II to the Fourth Assessment Report of the Intergovernmental Panel on Climate Change, 2007. Cambridge University Press, Cambridge, UK 2007

[9] International Federation of Red Cross and Red Crescent Societies. Central America, Mexico and Haiti: Floods from hurricanes. International Federation Press Publication No. 05-EA021, 2005.

[10] Magrin G, García CG, Cruz Choque D, et al. Latin America. In: Parry ML, Canziani OF, Palutikof JP, van der Linden PJ, Hanson CE, Eds. Climate Change 2007: Impacts, adaptation and vulnerability. Contribution of Working Group II to the Fourth Assessment Report of the Intergovernmental Panel on Climate Change 2007; pp. 581-615.

[11] Walther GR, Post E, Convey P, et al. Ecological responses to recent climate change. Nature 2002; 416: 389-95.

[12] Science Daily. Killer fungus threatening amphibians. Sci Daily November 24, 2009. 
[13] Crick HQP. Migratory species and climate change: Impacts of a changing environment on wild animals. United Nations Environment Programme (UNEP) / Convention on Migratory Species (CMS), Bonn, Germany 2006

[14] Malakata M. Seeds of capacity building in African agriculture. Regional Universities Forum for Capacity Building in Agriculture RUFORUM Monthly Newsletter 2007; vol. 1: pp. 3-4.

[15] Arocena R, Senker P. Technology, inequality, and underdevelopment: The case of Latin America. Sci Technol Hum Values 2003; 28: $15-33$.

[16] Pretty JN, Morison JIL, Hine RE. Reducing food poverty by increasing agricultural sustainability in developing countries. Agric Ecosyst Environ 2003; 95: 217-34.

[17] Gallopin GC. Linkages between vulnerability, resilience, and adaptive capacity. Global Environ Change 2006; 16: 293-303.

[18] Lorenzoni I, Jordan A, Favis-Mortlock DT, Viner D, Hall J. Developing sustainable practices to adapt to the impacts of climate change: a case study of agricultural systems in eastern England (UK). Region Environ Change 2001; 2: 106-17.

[19] Wall E, Smit B. Climate change adaptation in light of sustainable agriculture. J Sustainable Agric 2005; 27: 113-23.

[20] Nhemachena C, Hassan RM. Micro-level analysis of farmers adaptation to climate change in Southern Africa. International Food Policy and Research Institute, Division of Environment and Production Technology; Washington, D.C. 2007; Discussion Paper No. 007-14.

[21] Nyong A, Adesina F, Osman-Elasha B. The value of indigenous knowledge in climate change mitigation and adaptation strategie in the African Sahel. Mitigat Adapt Strategies Global Change 2007; 12: 787-97.

[22] Rahman A. Climate change and the future of smallholder agriculture. United Nations Department of Economic and Social Affairs. Commission on Sustainable Development, $16^{\text {th }}$ Session, New York May $5^{\text {th }}$ to $16^{\text {th }}, 2008$.

(c) Smith and Oelbermann; Licensee Bentham Open.

This is an open access article licensed under the terms of the Creative Commons Attribution Non-Commercial License (http://creativecommons.org/licenses/ by-nc/3.0/) which permits unrestricted, non-commercial use, distribution and reproduction in any medium, provided the work is properly cited. 